\title{
CrimRxiv
}

\section{Access Controlled: The Shaping of Power, Rights, and Rule in Cyberspace}

Ronald Deibert, John Palfrey, Rafal Rohozinski, Jonathan L. Zittrain

Published on: Apr 01, 2010

DOI: $10.21428 / c b 6 a b 371.3 d 7364 a 1$

License: Creative Commons Attribution 4.0 International License (CC-BY 4.0). 
